\title{
Knowledge on Marriage and Reproduction in Islam for Multicultural Healthcare and Social Work Needs: Results of the Survey at Five Public Universities in Slovakia
}

\section{Zavis (Monika Zavis)1', I. E. Voronkova (Irina Evgenjevna Voronkova)², P. Ch. Biswas (Parimal Chandra Biswas) ${ }^{3}$, L. Koldeova (Lujza Koldeova) $)^{1}$, M. Olah (Michal Olah)4, V. Krcmery (Vladimir Krcmery) ${ }^{5}$, R. Soltes (Radovan Soltes)' ${ }^{6}$, V. Juhas (Vladimir Juhas) H. Tkacova (Hedviga Tkacova) ${ }^{8}$, M. Bizon (Michal Bizon)') , J. Lenc (Jozef Lenc) ${ }^{10}$}

${ }^{1}$ Comenius University in Bratislava, Faculty of Education, Department of Original Article Pedagogy and Social Pedagogy, Slovakia.

${ }^{2}$ Oryol state University named after I. S. Turgenev, Oryol, Faculty of History, Dean of the faculty, Russian Federation.

${ }^{3}$ Adamas University, Kolkata, School of Economics and Business, Department of Management, India.

${ }^{4}$ University of Healthcare and Social Work of Ss. Elisabeth, n. o., Department of Social Work Jan Havlik Skalica, Slovakia.

${ }^{5}$ Comenius University in Bratislava, Faculty of Medicine, Department of Microbiology, Slovakia. University of Health and Social Work St. Elizabeth and Institute of tropical dis Slovak Medical University, School of Nursing,Bratisava

${ }^{6}$ University of Presov, Greek-Catholic Theological Faculty, Department of Philosophy and Religion, Slovakia.

${ }^{7}$ Catholic University in Ruzomberok, Faculty of Theology, Department of Systematic Theology, Slovakia.

${ }^{8}$ University of Zilina in Zilina, Faculty of Humanities, Department of Philosophy and Religious Studies, Slovakia.

${ }^{9}$ Comenius University in Bratislava, Faculty of Education, Department of Ethics and Civic Education, Slovakia.

${ }^{10}$ University of Ss. Cyril and Methodius in Trnava, Faculty of Arts, Department of Philosophy and Applied Philosophy, Slovakia.

\section{E-mail address:}

zavis@fedu.uniba.sk

\section{Reprint address:}

Monika Zavis

Comenius University in Bratislava

Faculty of Education

Department of Pedagogy and Social Pedagogy

Racianska 59

81334

Bratislava

Slovakia

Source: Clinical Social Work and Health Intervention Pages: $68-72$

\section{Reviewers:}

Selvaraj Subramanian

SAAaRMM, Kuala Lumpur, MY 
Roberto Cauda

Institute of Infectious Diseases, Catholic University of the Sacred Heart, Rome, IT

\section{Keywords:}

Islam. Marriage. Reproductive Health. Multicultural Healthcare. Multicultural Social Work.

\section{Publisher:}

International Society of Applied Preventive Medicine i-gap

CSWHI 2021; 12(2): 68 - 72; DOI: 10.22359/cswhi_12_2_13 (C) Clinical Social Work and Health Intervention

\section{Abstract:}

Objective: The aim of our research was to find out, if university students of humanities and social sciences at five Slovak public universities have theoretical prerequisites for intercultural competencies mainly needed in multicultural healthcare. These concrete theoretical prerequisites are dealing with knowledge regarding Islamic teachings on: family; female infanticide; reproduction; usage of assisted reproduction technologies; and induced abortion.

Design: Research study.

Participants: Overall 1000 students at 5 Slovak public universities (at each $n=200$ ).

Methods: Empirical research was done using our own questionnaire. Verification of our three hypotheses has been done using the method of statistical testing for testing hypotheses on equality of parameters of two alternative divisions with large selection ranges.

Results: Responses to questions concerning definition of marriage in Islam (Questions \#1 - 3) have shown, that both male and female students have proved better knowledge of this issue than in the case of the area concerning possibilities of use of reproductive medicine achievements in Islam. Responses to question (Question \#4) regarding Muhammad's attitude to feminine infanticide have shown that men, in comparison to women, have manifested more radical (more numerous) inclination to the answer that Muhammad entrusted fathers with decision on its performance. Responses to questions dealing with possibilities to use reproductive medicine achievements in Islam (Questions \#5-7) have shown that female, in comparison to male students, have manifested more radical (more numerous) rejective position.

Conclusion: Knowledge of marriage and reproductive issues in Islam among students stays at historical level, what causes a problem not to be able to understand and respect contemporary needs of Muslim patients in the frame of an holistic approach in multicultural healthcare and social work in Slovakia. Improvements in current curriculum concerning students' intercultural competencies mainly connected to an understanding of standpoints of Muslim believers concerning their social foundations, health and entire well-being are inevitable. 


\section{Introduction}

Although European and American society is now for almost a yearlong faced in a priority manner with COVID-19 pandemic which places high ethical and hygienic demands on professionals of diverse domains and both challenges ordinary people to act reasonable and responsible we shouldn't be approaching human dignity and overall well-being reducing them to numbers or statistic reports concerning the spread of the disease (WHO, 2020). Even in these times of virtual interpersonal relationships we have to be aware of the importance of our approach to the most inner values and religious worldview which are constitutional parts of everyone's existence. Regarding Islam, which is still often perceived as an exotic element to European culture, regardless to its historical cross connection with European culture, it is important to overcome ungrounded xenophobia (Dojcar, 2017) and authentically try to understand the most personal, intimate stands of believers (Zavis, Prochazka, 2020) who need our help dealing with health, social or educational issues.

\section{Methods}

This study presents chosen results of the research that was conducted in the frame of the project Bioethics of Reproductive Health in Islam: Basis, Discussion and Challenges, VEGA $\# 1 / 0585 / 18$, which is unique both regarding contemporary Slovak research; its past research; and that of an entire European context. Quantitative research on the topic of theoretical preparedness for intercultural or interreligious communication has been conducted at: Comenius University in Bratislava; University of Ss. Cyril and Methodius in Trnava; University of Zilina in Zilina; University of Presov in Presov; Catholic University in Ruzomberok; at each university $n=200$, totally $\mathrm{n}=1000$.

\section{Evaluation of Empirical Research}

Verification of 3 given research hypotheses has been done using the method of statistical testing for testing hypotheses on equality of parameters of two alternative divisions with large selection ranges. Our approach was based on following criteria given by statistical testing according to Markechova et al. (2011):

We assume that:
$\left(\mathrm{X}_{11}, \mathrm{X}_{12}, \ldots \ldots \ldots . . ., \mathrm{X}_{1 \mathrm{n} 1}\right)$ is a random pick from division of alternative $p_{1}\left(p_{1}\right.$ means probability of hypothesis $\mathrm{H} 0$ ),

$\left(\mathrm{X}_{21}, \mathrm{X}_{22}, \ldots \ldots \ldots, \mathrm{X}_{2 \mathrm{n} 2}\right)$ is a random pick from division of alternative $\mathrm{p}_{2}\left(\mathrm{p}_{2}\right.$ means probability of hypothesis $\mathrm{H} 1$ ).

The selections are independent:

$$
\mathrm{n}_{1}>50 \mathrm{a} \sum_{i=1}^{n_{1}} X_{1 i}+\sum_{i=1}^{n_{2}} X_{2 i}>5 \text {. }
$$

We are testing the problem:

H0: $p_{1}=p_{2}$ against H1: $p_{1}<p_{2} ; p_{1}>p_{2}$

$$
\begin{aligned}
& \overline{X_{1}}=\frac{1}{n_{1}} \sum_{i=1}^{n_{1}} X_{1 i} \\
& \overline{X_{2}}=\frac{1}{n_{2}} \sum_{i=1}^{n_{2}} X_{2 i} \\
& \bar{X}=\frac{n_{1} \overline{X_{1}}+n_{2} \overline{X_{2}}}{n_{1}+n_{2}}
\end{aligned}
$$

The value of testing criterion:

H0: $p_{1}=p_{2}$ against H1: $p_{1}<p_{2}$ :

Critical domain $\mathrm{W}_{0.05}=\left(-\infty ;-\mathrm{u}_{2.0 .05}\right)=(-\infty$; $\left.-\mathrm{u}_{0,1}\right) \mathrm{u}_{0.1}$ is critical value $\mathrm{N}(0.1)$ according to division of critical values of $u_{\alpha}$ division $N(0.1)$ in Table $1 \mathrm{u}_{0.1}=1.64$

$\mathrm{W}_{0,05}=(-\infty ;-1.64)$ Hypothesis testing:

$\mathrm{U} \in \mathrm{W}_{0.05}$, then we reject $\mathrm{H} 0$ and $\mathrm{H} 1$ is valid.

$\mathrm{U} \notin \mathrm{W}_{0.05}$, then $\mathrm{H} 0$ is valid and we reject $\mathrm{H} 1$.

H0: $\mathbf{p}_{1}=\mathbf{p}_{\mathbf{2}}$ against H1: $\mathbf{p}_{\mathbf{1}}>\mathbf{p}_{\mathbf{2}}$ :

Critical domain W0.05 $=(\mathrm{u} 2.0 .05 ; \infty)=$ $(\mathrm{u} 0.1 ; \infty) \mathrm{u}_{0,1}$ is critical value $\mathrm{N}(0.1)$ according to division of critical values of $\mathrm{u}_{\alpha}$ division $\mathrm{N}(0.1)$ in Table $1_{\mathrm{u} 0,1}=1.64$

W0.05 $=(1.64 ; \infty)$

Hypothesis testing:

$\mathrm{U} \in \mathrm{W}_{0.05}$, then we reject $\mathrm{H} 0$ and $\mathrm{H} 1$ is valid. $\mathrm{U} \notin \mathrm{W}_{0.05}$, then $\mathrm{H} 0$ is valid and we reject $\mathrm{H} 1$. Critical values of $\mathrm{u} \alpha$ division $\mathrm{N}(0.1)$;

$\mathrm{X} \sim \mathrm{N}(0.1), \mathrm{P}(|\mathrm{X}|>\mathrm{u} \alpha)=\alpha$

Table 1 Critical values of $\mathrm{u}$ division $\mathrm{N}(0,1)$

\begin{tabular}{|l|l|l|l|l|}
\hline$\alpha$ & 0.01 & 0.02 & 0.05 & 0.1 \\
\hline $\mathrm{u} \alpha$ & 2.5758 & 2.3263 & 1.9599 & 1.6448 \\
\hline
\end{tabular}




\section{The Results of Empirical Research}

\section{Hypothesis 1:}

Hypothesis 1.0: Both men and women won't manifest better knowledge of this issue than in the case of the area concerning possibilities of the use of reproductive medicine achievements in Islam.

Hypothesis 1.1: Both men and women will manifest better knowledge of this issue than in the case of area concerning possibilities of use of reproductive medicine achievements in Islam.

Statistical testing: $\mathrm{U}=-26.4$ where $\mathrm{U} \in \mathrm{W}=$ $(-\infty ; 1.64)$ while testing $\mathrm{H} 0: \mathrm{p}_{1}=\mathrm{p}_{2}$ against $\mathrm{H} 1$ : $\mathrm{p}_{1}<\mathrm{p}_{2}$ at the level of significance $\alpha=0.1$ we state that hypothesis 1.0 has not been confirmed and hypothesis 1.1 has been confirmed.

\section{Figure 1 Comparison of knowledge dealing with definition of marriage and reproductive medicine in Islam (\%)}

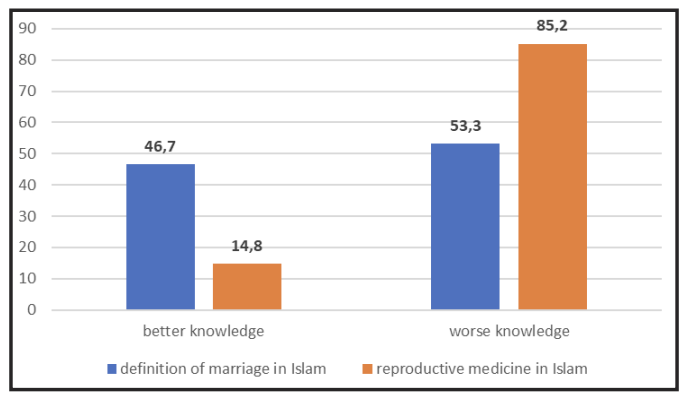

\section{Hypothesis 2:}

Hypothesis 2.0: Men, in comparison to women, will not manifest more radical (multiple) inclination to the answer that Muhammad entrusted fathers with decision on its performance.

Hypothesis 2.1: Men, in comparison to women, will manifest more radical (multiple) inclination to answer that Muhammad entrusted fathers with decision on its performance.

Statistical testing: $\mathrm{U}=2.88$ where $\mathrm{U} \in \mathrm{W}=$ $(\infty ; 1.64)$ while testing $\mathrm{H} 0: \mathrm{p}_{1}=\mathrm{p}_{2}$ against $\mathrm{H} 1$ : $\mathrm{p}_{1}>\mathrm{p}_{2}$ at the level of significance $\alpha=0.1$ we state that hypothesis 2.0 has not been confirmed whereas hypothesis 2.1 has been confirmed.
Figure 2 Positions of men and women on feminine infanticide in Islam (\%)

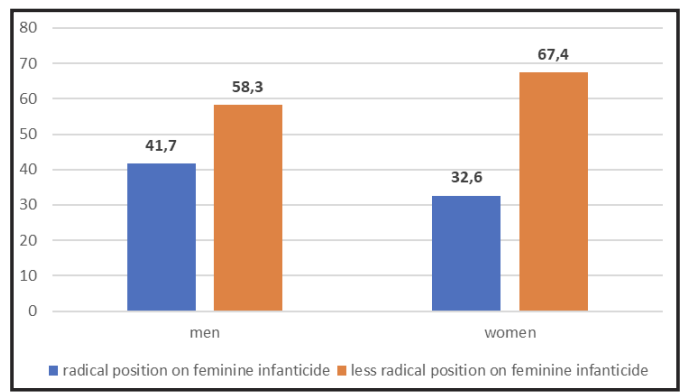

\section{Hypothesis 3:}

Hypothesis 3.0: Women, in comparison to men, won't manifest more radical (multiple) rejective position.

Hypothesis 3.1 Women, in comparison to men, will manifest more radical (multiple) rejective position.

Statistical testing: $\mathrm{U}=-6,493$, where $\mathrm{U} \in \mathrm{W}=$ $(-\infty ;-1.64)$ while testing $\mathrm{H} 0: \mathrm{p}_{1}=\mathrm{p}_{2}$ against $\mathrm{H} 1$ : $\mathrm{p}_{1}<\mathrm{p}_{2}$ at the level of significance $\alpha=0.1$ we state that hypothesis 3.0 has not been confirmed whereas hypothesis 3.1 has been confirmed.

Figure 3 Attitudes of men and women to reproductive medicine in Islam (\%)

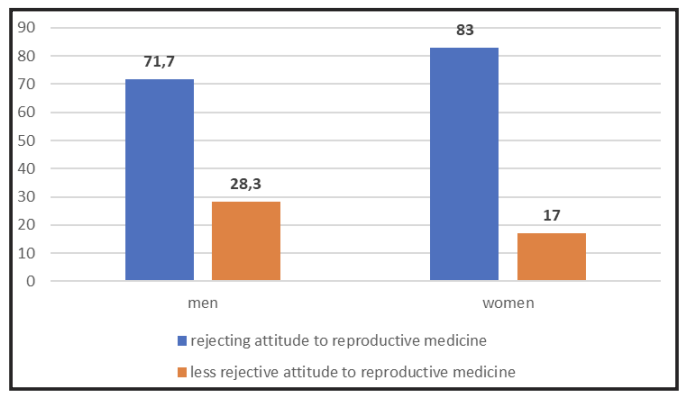

\section{Discussion and Conclusion}

The results of our quantitative research show that knowledge of marriage and reproductive issues in Islam among students stays at an historical level gained by lectures that in a reducing manner accentuate historically axiomatic individual and social principles in Islam what causes a problem not to be able to understand and respect contemporary needs of Muslim patients in the frame of holistic approach in multicultural healthcare and social work in Slovakia. Improvements in current curriculum concerning students' 
intercultural competencies mainly connected to understanding of standpoints of Muslim believers concerning their social foundations, health and entire well-being are inevitable. There is also an open question of preparedness of university lecturers and professors regarding the quality of their lectures, as the same as their empirical experience stemming from personal affinity to know deeper other cultures and religions as to be able to understand contemporary standpoints of believers professing other faiths; that means to be willing to go beyond ritual praxis and search for their spiritual motivation on an existential level. The present and the future of religions are of the same importance as their history. The fact that religions evolve both by their doctrines and praxis is also very important, and that means that for a teacher preparing students for interreligious communication or providing healthcare is inevitable to follow changes in particular religions and to communicate them to students with appropriate interpretation. Therefore, it is necessary to start to critically evaluate the current content of lectures regarding religions with a special emphasis on a place of the modern human, believer and his/her needs, issues, challenges in the frame of the religion he/she belongs to. It is considerably contra-productive to academically prepare future health workers, social workers, teachers or other professionals in humanities or social sciences exclusively by leading them to memorize particular quotations from the sacred scriptures regarding a particular topic and not to be able to apply their sense to needs and requests of contemporary patient or a person in whatever distress, emergency or need. Further research and identification of reasons or premises leading to unsatisfactory results regarding students' knowledge of current marital and reproductive issues of Muslim couples in the context of their religious background is needed.

\section{Declaration on Interest}

The authors declare that they have no conflict of interest.

\section{Acknowledgements}

The article is written within the frame of the VEGA project \#1/0585/18: Bioethics of Reproductive Health in Islam: Basis, Discussion and Challenges (2018 - 2019). The project was suc- cessfully finalized at Comenius University, Faculty of Education, Department of Pedagogy and Social Pedagogy and proclaimed by VEGA Commission at the Ministry of Education, Science, Research and Sport of the Slovak Republic to be one of projects with best research results.

\section{References:}

1. DOJCAR M (2017) Migration, Xenophobia and Dialogical Ethos. In Migration: Religions without Borders - European Perspective. Trnava: Trnava University.

2. MARKECHOVA D, STEHLIKOVA B, TIRPAKOVA A (2011) Statistical Methods and Their Application. Nitra: Constantine the Philosopher University in Nitra.

3. KUBA K, KUBOVA S, HARSA P, PAVLU S (2020) Linking psychology with physiotherapy within rehabilitation, Rehabilitation, Vol. 57, no. 4, 2020, ISSN 0375-0922, p. 307.

4. WORLD HEALTH ORGANIZATION (2020) WHO Coronavirus Disease (COVID19) Dashboard. [cited 2020 Oct. 12]. Available at: https://covid19.who.int/table.

5. ZAVIS M, PROCHAZKA P (2020) Studying Spirituality of Muslim Spouses Fighting Infertility: From Methodological Problems to Analysis of Everyday Practice. Spirituality Studies 6(2): pp 28-39. 